07,11

\title{
Структурные фазовые переходы в $\alpha$-титане, содержащем неметаллические микропримеси
}

\author{
() В.И. Савенко ${ }^{1}$, Л.И. Куксенова ${ }^{1,2}$, Р.Р. Хасбиуллин ${ }^{1}$, А.А. Ширяев ${ }^{1}$ \\ ${ }^{1}$ Институт фризической химии и электрохимии им. А.Н.Фрумкина РАН, \\ Москва, Россия \\ ${ }^{2}$ Институт машиноведения им. А.А. Благонравова РАН, \\ Москва, Россия \\ E-mail: visavenko@phyche.ac.ru
}

Поступила в Редакцию 12 ноября 2019 г.

В окончательной редакции 24 декабря 2019 г.

Принята к публикации 9 января 2020 г.

Методами дифференциальной сканирующей калориметрии (ДСК), дифференциальной термогравиметрии (ДТГА), массспектрометрии и рентгеноструктурного анализа (РСА) исследованы структурные фазовые переходы в содержащем неметаллические микропримеси порошковом $\alpha$-титане при повышенных температурах. Определены микроструктурные и энергетические характеристики этих переходов.

Ключевые слова: титан, нестехиометрические фазы внедрения, структурные фазовые переходы, дифференциальная сканирующая калориметрия, рентгеноструктурный анализ.

DOI: 10.21883/FTT.2020.07.49474.626

\section{1. Введение}

Частицы порошкового титана промышленного производства, как правило, содержат сравнительно небольшое количество неметаллических примесей [1]. Такие примеси могут входить в решетку $\alpha$-титана конгруэнтно - как внедренные атомы, образуя твердый раствор. Они также могут выделяться в титановой матрице в виде микровключений инородных фаз $\mathrm{Ti}_{x} \mathrm{~A}_{y}$ и $\mathrm{Ti}_{x} \mathrm{~B}_{y} \mathrm{Cz}$ нестехиометрического состава [2]. Очевидно, что наличие указанных структурных особенностей не может не влиять на температурное поведение данного материала. В частности, в такой системе при температурных вариациях возможны структурные фазовые переходы, оставляющие неизменной кристаллическую решетку металла [3-6]. Учет упомянутых переходов особенно важен при разработке технологий аэрокосмического и медицинского назначения, использующих порошковый титан в качестве исходного сырья [7,8]. Вместе с тем, в научной литературе имеются лишь публикации, посвященные исследованию структурных фазовых переходов $(\alpha \rightarrow \beta$, или $\alpha \rightarrow \omega)$, меняющих кристаллическую решетку $\alpha$-титана при повышенных температурах, давлениях или ударных нагрузках [9-15], а также исследования $\alpha \rightarrow \omega$ переходов, происходящих при большом содержании кислородной примеси в титане [16]. Согласно известным авторам литературным данным, исследования влияния микропримесей на структурные фазовые переходы, оставляющие неизменной кристаллическую решетку $\alpha$-титана, до настоящего времени не проводились.

Настоящая работа посвящена обнаружению и анализу структурных фазовых переходов, возможных в содержащем неметаллические микропримеси порошковом титане при температурных вариациях, не выходящих за пределы области температурной стабильности его $\alpha$-фазы.

\section{2. Образцы и методика}

Анализировали титановый порошок промышленного производства марки ПТМ-1 (ТУ 14-22-57-92), полученный восстановлением оксидов металла гидридом кальция. Элементный состав порошка представлен в табл. 1.

Температурное поведение образцов исследовали при помощи дифференциального сканирующего калориметpa NETZSCH DSC 204 F1 Phoenix в проточной атмосфере очищенного и осушенного аргона (скорость потока $30-50 \mathrm{ml} / \mathrm{min}$ ). Скорость нагрева и охлаждения образцов варьировали в интервале $2.5-20^{\circ} / \mathrm{min}$. Микроструктуру и фазовый состав порошковых частиц анализировали с применением рентгеновских дифрактометров Empyrean и Stoe Huber G670, позволявших проводить высокотемпературные испытания материалов в условиях вакуума при давлении не более $10^{-3} \mathrm{~Pa}$. Опыты проводили в высокотемпературной вакуумной камере НTK-1200N, оборудованной турбомолекулярным насосом и системой автоматической подстройки положения образца отно-

Таблица 1. Элементный состав порошковых частиц $\alpha$-титана

\begin{tabular}{|c|c|c|c|c|c|c|c|c|c|}
\hline \multirow[t]{2}{*}{$\mathrm{Ti}$} & \multicolumn{4}{|c|}{$\begin{array}{c}\text { Примеси внедрения, } \\
\text { масс.\% }\end{array}$} & \multicolumn{5}{|c|}{$\begin{array}{c}\text { Примеси замещения, } \\
\text { масс.\% }\end{array}$} \\
\hline & $\mathrm{H}$ & 011 & $\mathrm{O}$ & $\mathrm{N}$ & $\mathrm{Ca}$ & $\mathrm{Fe}$ & $\mathrm{Ni}$ & $\mathrm{Si}$ & $\mathrm{Al}$ \\
\hline & 0.30 & 0.12 & 0.25 & 0.10 & 0.1 & 0.05 & 0.06 & & 0.01 \\
\hline
\end{tabular}


сительно оси гониометра в геометрии „на отражение“ $\left(\mathrm{Cu} K_{\alpha}\right.$-излучение, никелевый фильтр, держатель образца - корундовая подложка).

Температура образца при нагреве и охлаждении изменялась ступенчато с шагом $20^{\circ}$, скорость изменения температуры между ступенями составляла $10^{\circ} / \mathrm{min}$, длительность экспозиции при съемке каждой дифрактограммы при фиксированной температуре $-30 \mathrm{~min}$. При расчетах дифрактограмм учитывали две длины волны $K_{\alpha 1}=1.540598$ и $K_{\alpha 2}=0.1544426 \mathrm{~nm}$ с соотношением интенсивностей линий в дублете $2: 1$. Измерения осуществляли в диапазоне углов отражения $2 \theta=25-120^{\circ}$ с шагом $0.0334^{\circ}$.

Для обнаружения гетерофазных реакций окисления (и/или разложения), которые предположительно могли бы протекать в порошке при его термоциклировании и для синхронного контроля возможных газообразных продуктов этих реакций, а также для анализа процессов десорбции газов из порошкового материала использовали методику дифференциального термогравиметрического анализа (ДТГА), дополненную масс-спектрометрическим определением состава газовой атмосферы в ТГА-камере. Эти исследования проводили с применением анализатора NetzschTG 209 F1 Iris, сопряженного с квадрупольным масс-спектрометром QMS 403 D Aeolos. Характеристики процесса ДТГ-анализа были следующие: диапазон температур $25-500^{\circ} \mathrm{C}$ скорость нагрева 10 и $20^{\circ} / \mathrm{min}$; эксперименты выполняли в инертной атмосфере очищенного и осушенного аргона при скорости его потока $30 \mathrm{ml} / \mathrm{min}$. Рабочие параметры QMS-анализатора: детектор CH-TRON, напряжени $1.2 \mathrm{kV}$, режим сканирования - MID (Multiple Ion Detection), время накопления сигнала (dwell time) $-1 \mathrm{~s}$. Нижний концентрационный предел детектирования $-10 \mathrm{ppm}$. Особое внимание уделялось детектированию следующих масс: $1,2,12,14,16,17,18,28,32,44$.

\section{3. Результаты и их обсуждение}

На рис. 1 в качестве типичного примера представлены результаты ДСК-термоанализа титанового порошка при его последовательном нагреве и охлаждении в интервале температур $50-500^{\circ} \mathrm{C}$.

Обнаружено наличие двух взаимно смещенных по шкале температур благодаря гистерезису эндо- и экзоэнергетических пиков, имеющих сложную структуру и соответствующих фазовым переходам 1 рода в системе. Во врезке к рис. 1 представлено разложение эндопика на 4 элементарных составляющих в приближении Лоренца. Значения пиковых температур $T_{i}$ этих составляющих, а также соответствующие им энтальпий $\Delta H_{i}$ (в расчете на единицу массы титана) приведены в табл. 2.

Анализ результатов ДТГ-экспериментов показал полное отсутствие каких-либо гетерофазных реакций в материале, включая процессы его окисления и термодеструкции при термоциклировании. Масс-спектромет-

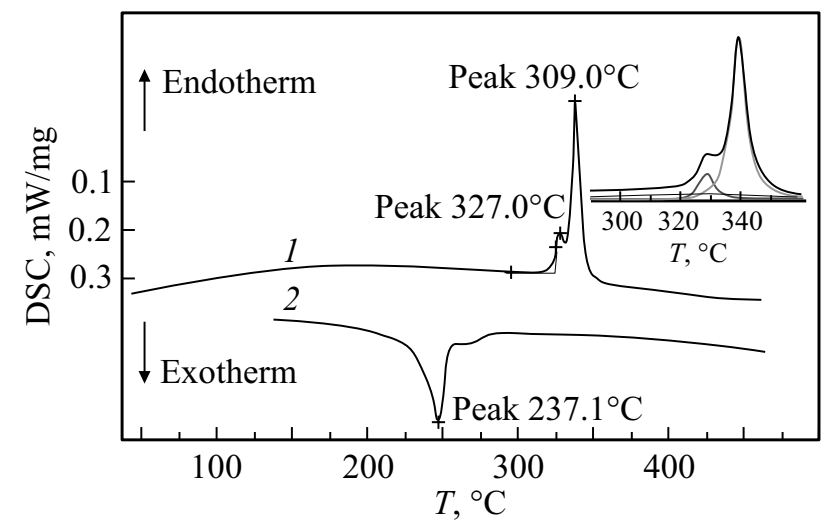

Рис. 1. ДСК-диаграммы, полученные при нагреве (1) и охлаждении (2) порошкового титана. Скорость изменения температуры $10^{\circ} / \mathrm{min}$.
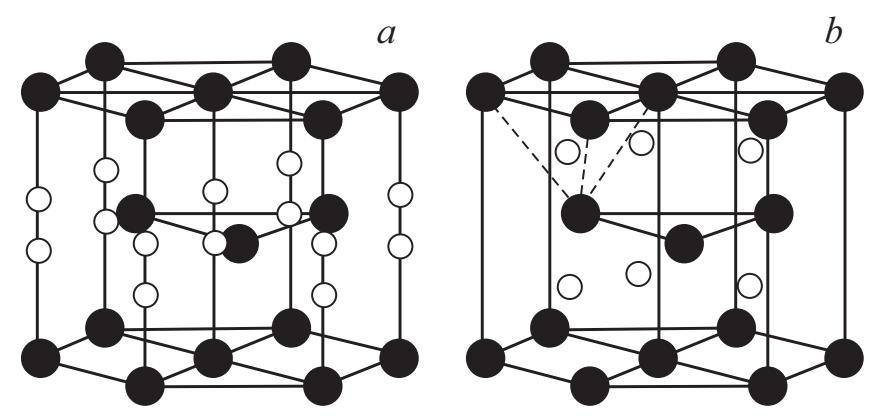

Рис. 2. Октаэдрические $(a)$ и тетраэдрические $(b)$ междоузельные пустоты (обозначены белыми сферами) в ГПУ-кристаллической решетке $\alpha$-титана (показаны не все тетраэдрические пустоты).

рический анализ также не обнаружил десорбцию атомов, или молекул водорода, углерода, азота, кислорода, воды и углекислого газа из порошкового материала в температурном интервале локализации ДСК-эндопика $\Delta T=300-400^{\circ} \mathrm{C}$. Таким образом, можно полагать, что вышеуказанный эндопик, равно как и сопряженный ему экзопик, обусловлены структурными фазовыми переходами в материале порошковых частиц при их нагреве и охлаждении.

Как известно, примеси, внедрения в ГПУ-решетке $\alpha$-титана могут располагаться в ее октаэдрических $(O)$ и тетраэдрических $(T)$ междоузельных пустотах $(O-$ и $T$-нанопорах - рис. 2).

Таблица 2. Энергетические характеристики элементарных эндопиков

\begin{tabular}{c|c|c|c|c|c}
\hline$i$ - № пика & 1 & 2 & 3 & 4 & $\Delta T_{t r}$ \\
\hline$T_{i},{ }^{\circ} \mathrm{C}$ & 300.9 & 328.6 & 328.7 & 339.2 & $270-370$ \\
\hline \multirow{2}{*}{$\Delta H_{i}, \mathrm{~J} / \mathrm{g}$} & 1.5 & 1.5 & 2.7 & 13.3 & $\sum_{i} \Delta H_{i}$ \\
\cline { 4 - 5 } & & & & & 19
\end{tabular}


В элементарной ячейке титана на 6 атомов металла (радиусом $R_{m}$ ) приходится $N_{O}=6$ октаэдрических $\left(r_{O}=0.41 R_{m}\right)$, и $N_{T}=12$ тетраэдрических $\left(r_{T}=0.228 R_{m}\right)$ нанопор. Они образуют в кристаллической решетке титана две $O$ - и $T$-подрешетки, заполненные атомами примесей лишь частично благодаря весьма незначительным их концентрациям, суммарно не превышающим величину, равную нескольким атомным процентам (см. табл. 1). В таком случае подсистема „примесные атомы-вакансии“ в каждой из подрешеток может рассматриваться в качестве твердого раствора замещения, в котором возможно установление дальнего порядка с образованием сверхструктурных фаз [3-6]. Учитывая, что в данном порошковом материале имеется четыре вида примесей внедрения (см. табл. 1), в соответствующих $O$ - и $T$-подрешетках при достаточно низких температурах может образоваться четыре типа сверхструктур [4], характеризующихся четырьмя параметрами дальнего порядка $\eta_{i}$, где $i=\{\mathrm{H} ; \mathrm{C} ; \mathrm{N} ; \mathrm{O}\}$.

Поскольку внедренные атомы занимают в $O$ - и $T$-подрешетках наборы геометрически и энергетически неэквивалентных положений, различающиеся для каждого сорта примесей, структурные фазовые переходы в них происходят при различных температурах (см. табл. 2). Однако из-за относительной близости энергий взаимодействия $u_{i i}^{O}$ и $u_{i i}^{T}$ между внедренными в соответствующие подрешетки атомами сорта $i$, а также благодаря выравниванию энергий взаимодействия $U_{M i}^{k}$ (где $k=O$, или $T$ ) между внедренными атомами сорта $i$ и атомами титановой матрицы $M$, температуры этих переходов различаются незначительно. Это дает возможность использовать при оценке энергетических характеристик системы приближение среднего поля, не требующее конкретизации вида внедренных атомов. Полученная в рамках указанного приближения оценка энергии взаимодействия $\overline{u_{i}}$ таких „обезличенных“ атомов между собой (без дифференциации числа межатомных связей $i-i$, приходящихся на один внедренный атом $i$ в соответствующих подрешетках) дает значение $\overline{u_{i}} \approx\left(\sum_{i=1}^{4} \Delta H_{i}\right) \cdot\left(\sum_{i=1}^{4} \Delta m_{i}\right) / 4 \cdot \sum_{i=1}^{4} C_{i}$ $\approx-0.283 \mathrm{eV}$. (Здесь $m_{i}$ - атомная масса $i$-го примесного элемента, $C_{i}-$ его массовая доля в частицах порошка). Учет геометрического и энергетического различия положений примесных атомов, внедренных в $O$ и $T$-подрешетки, позволяет оценить в локально-координационном приближении энергии их индивидуальных межатомных связей $u_{i j}^{k}$ (где $k=O$ или $T$ ).

Действительно, пусть $P_{i j}^{k}$ есть вероятность заполнения междоузлия, находящегося вблизи „обезличенного“ атома $i$ в подрешетке вида $k$, однотипным и внедренным в ту же подрешетку атомом $j$. Тогда из очевидного соотношения $\overline{u_{i}}=\left[0.5 /\left(N^{O}+N^{T}\right)\right] \cdot \sum_{k=O, T}\left[\sum_{i, j=1}^{N^{O}+N^{T}}\right] u_{i j}^{k} p_{i j}^{k}$, связывающего в локально-координационном приближении среднюю энергию взаимодействия между однотипными внедренными атомами $\overline{u_{i}}$ с энергией индивидуальных межатомных связей между ними $u_{i j}^{k}$, можно получить оценку значений энергии связи между „обезличенными“ атомами $i-i$, соседствующими в первой координационной сфере радиуса $r_{1}$ в $O$ - и $T$-подрешетках $\alpha$-титана: $u_{i i}^{O}\left(r_{1}\right) \approx 0.5 u_{i i}^{T}\left(r_{1}\right) \approx(1 / 7.44) \overline{u_{i}}=-3.8 \cdot 10^{-2} \mathrm{eV}$

В данном расчете было учтено взаимодействие между внедренными атомами, локализованными лишь в первых двух (с радиусами $r_{1}$ и $r_{2}$ ) координационных сферах $O$ - и $T$-подрешеток При этом были использованы следующие приближенные соотношения $u_{i i}^{O}\left(r_{1}\right) \approx 3 u_{i i}^{O}\left(r_{2}\right)$, $u_{i i}^{T}\left(r_{1}\right) \approx 2 u_{i i}^{T}\left(r_{2}\right)$ и $u_{i i}^{O}\left(r_{1}\right) \approx 0.5 u_{i i}^{T}\left(r_{1}\right)$, допустимые при оценке энергий взаимодействия между однотипными (обезличенными) атомами $i$ в структурах рассматриваемого типа.

В рамках вышеуказанного приближения можно также получить оценочное соотношение для энергий взаимодействия однотипных атомов, располагающихся в первой и второй координационных сферах октаэдрической ГПУ-подрешетки: $u_{i i}^{O}\left(r_{2}\right) \approx 0.33 u_{i i}^{O}\left(r_{1}\right)$ $\approx-1.27 \cdot 10^{-2} \mathrm{eV}$. Их сумма в данном случае оказывается равной $u_{i i}^{O}\left(r_{1}\right)+u_{i i}^{O}\left(r_{2}\right)=-5.07 \cdot 10^{-2} \mathrm{eV}$, т. е. приближается к значению, которое при заданной точности структурно-энергетических оценок определяет величину поглощенной при фазовом переходе удельной тепловой энергии $Q \cong-k_{\mathrm{B}} \cdot \bar{T}_{t r}=-5.14 \cdot 10^{-2} \mathrm{eV}$. (Здесь $k_{\mathrm{B}}$ - константа Больцмана, а величина $\bar{T}_{t r}=(1 / 4) \sum_{i=1}^{4} T_{i}$ $=597.5^{\circ} \mathrm{K}$ ). Близость значений этих энергетических характеристик является косвенным указанием на то обстоятельство, что при наблюдаемом фазовом переходе в ГПУ-структуре происходит одновременный разрыв связей между атомами, внедренными в $O$-подрешетку, и их передислокация в конфигурации, связанные с $T$-подрешеткой.

Очевидно, что рассматриваемые фазовые переходы должны отражаться также и на температурном поведении параметров решетки $\alpha$-фазы титана. На рис. 3

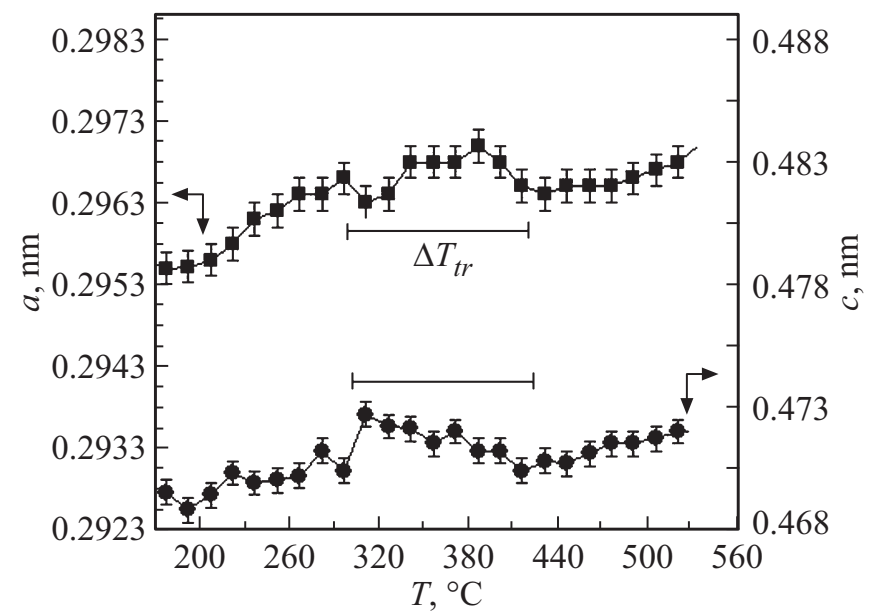

Рис. 3. Температурная зависимость параметров кристаллической решетки $\alpha$-титана, полученная при последовательном нагреве порошкового образца. Горизонтальной линией отмечен температурный интервал $\Delta T_{t r}$ фазовых переходов. 
приведена зависимость параметров элементарной ячейки $\alpha$-титана, полученная при ступенчатом нагреве порошковой пробы. Обнаружено существенно немонотонное изменение этих параметров в температурном интервале $\Delta T_{t r}=300-400^{\circ} \mathrm{C}$, покрывающем область температур, соответствующих вышеупомянутым структурным фазовым переходам на ДСК-диаграммах. При возрастании температуры в указанном температурном интервале базисный параметр $a[10 \overline{1} 0]$ решетки Браве $\alpha$-титана после кратковременного спада продолжает увеличивается, а призматический параметр $c$ [0001] претерпевает заметный спад (что свидетельствует об отрицательном значении соответствующей компоненты тензора коэффициентов термического расширения). Отношение $c / a$ при этом уменьшается от стандартного значения $c / a=1.588[17]$ при $25^{\circ} \mathrm{C}$ до значения $c / a=1.585$ в начале фазового перехода и принимает значение $c / a=1.582$ к его концу. Это свидетельствует о появлении тетраэдрических искажений элементарной ячейки кристаллической решетки $\alpha$-титана, которые вызваны перемещением части ведренных атомов, локализованных ранее преимущественно в принадлежащих призматическим плоскостям более крупных октадрических нанопорах, в лежащие в базисных плоскостях малоразмерные тетраэдрические нанопоры.

Проведенный по методике [4] структурно-энергетический анализ уравнений термодинамического равновесия системы, построенных в приближении среднего поля для различных значений $q=n /\left(N^{O}+N^{T}\right)$, (где $n=\sum_{i}^{4} n_{i}-$ суммарная атомная концентрация примесей внедрения, приходящаяся на элементарную ячейку ГПУ-решетки $\alpha$-титана) приводит к заключению, что распределение примесных атомов в микроструктуре $\alpha$-титана носит существенно неоднородный характер. Структурные фазовые переходы в $\alpha$-титане оказываются возможными лишь в том случае, если при достаточно низких гомологических температурах в решетке $\alpha$-титана имеются области субмикрометрических размеров, образующие в матрице $\alpha$-титана ультрамикродисперсную фазу (микрофазу), значительно обогащенную примесными атомами. Эту микрофазу можно рассматривать в качестве совокупности выделений коллоидных размеров в матричной ГПУ решетке $\alpha$-титана, которая служит для такой микрофазы дисперсионной средой. С металловедческой точки зрения эта микрофаза является аналогом совокупности наноразмерных зон Гинье-Престона, наблюдаемых в алюминиевых и некоторых других сплавах при их старении [18].

Относительная концентрация примесных атомов в междоузлиях этих микрообластей может достигать величины $q=0.25-0.3$, приближаясь к концентрации междоузлий $v=N^{O} /\left(N^{O}+N^{T}\right)=1 / 3$ в $O$-подрешетке $\alpha$-титана. Именно в микрообъемах этой коллоиднодисперсной микрофазы в соответствующих $O$ - и $T$-подрешетках ГПУ-структуры при нагреве и охлаждении материала происходят вышеупомянутые структурные фазовые переходы 1 рода.

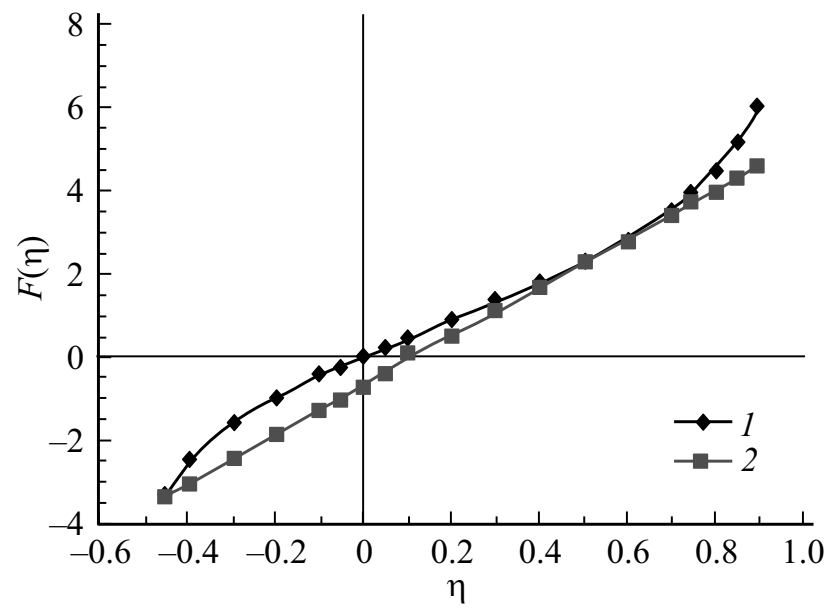

Рис. 4. Графоаналитическое решение трансцендентного уравнения (1): 1 - функция $L(\eta), 2-$ функция $y=\left(R_{1} \eta+R_{2}\right) / k_{\mathrm{B}} \bar{T}_{t r}$.

Уравнение термодинамического равновесия для системы для случая $q=v=1 / 3$ является трансцендентным относительно параметров дальнего порядка $\eta_{i}$. Записанное в рамках локально-координационного приближения при вышеуказанных энергетических ограничениях, но без учета деформационного взаимодействия и ближнего порядка в системе [4,5] оно имеет вид [4]:

$$
L(\eta) \equiv \ln \left[\frac{(1+2 \eta)(2+\eta)}{2(1-\eta)^{2}}\right]=\left(R_{1} \eta+R_{2}\right) / k_{\mathrm{B}} \bar{T}_{t r},
$$

где

$$
\begin{gathered}
R_{1}=-(1-v) \sum_{i, j}\left(u_{i j}^{O} p_{i j}^{O}+u_{i j}^{O} p_{i j}^{O}+u_{i j}^{O} p_{i j}^{O}\right)=+0.308 \mathrm{eV} . \\
R_{2}=q\left\{\sum_{i, j}\left[\left(u_{i j}^{T} p_{i j}^{T}+u_{i j}^{T} p_{i j}^{T}\right)-\left(u_{i j}^{O} p_{i j}^{O}+u_{i j}^{O} p_{i j}^{O}\right)\right]\right\} \\
+\left(E_{T}-E_{O}\right)=-0.225 \mathrm{eV} .
\end{gathered}
$$

Здесь $E_{O}$ и $E_{T}$ - энергии межатомного взаимодействия внедренных атомов с атомами титана, соответственно, в $O$ - и $T$-подрешетках, полученные в рамках приближения среднего поля; $\eta=\left\langle\eta_{i}\right\rangle$ в этом же приближении.

Графоаналитическое решение уравнения (1) показано на рис. 4.

Численное решение уравнение (1), найденное методом последовательных приближений, показывает, что фазовые переходы в $O$ - и $T$-подрешетках сопровождаются резким изменением величины $\eta$ от положительных значений $\eta_{O} \approx+(0.65-0.70)$, характеризующих распределение внедренных атомов и вакансий в $O$-подрешетке, к отрицательным значениям $\eta_{T} \approx(0.45-0.46)$, описывающим распределение тех же структурных составляющих в $T$-подрешетке. Поскольку $\left|\bar{\eta}_{O}>\right| \bar{\eta}_{T} \mid$, то при таких фазовых переходах происходит заметное энергопоглощение в системе. Дальнейшее повышение температуры 
при $T>T_{t r}$ приводит к постепенному разупорядочению во взаимном расположении внедренных атомов, локализованных теперь преимущественно в $T$-подрешетке, и вакансий в ней (т.е. $\bar{\eta}_{T} \rightarrow 0$. При этом энергопоглощение в системе при росте температуры становится незначительным, или может вовсе отсутствовать. Благодаря тому, что энергия взаимодействия между однотипными атомами $i-i$, внедренными в соответствующие $O$ - и $T$-подрешетки, оказывается отрицательной, $\overline{u_{i}^{k}}<0$ (где по-прежнему $k=O$, или $T$ ), внедренные атомы в состоянии упорядочения в указанных подрешетках находятся в окружении преимущественно однотипных с ними атомов (но не вакансий). При этом фазовые переходы ,порядокбеспорядок“ сопровождаются процессами, формально аналогичными плавлению.

Противоположные изменения параметров решетки $\alpha$-титана наблюдаются при охлаждении образца в диапазоне температур, соответствующих экзопику на рис. 1 . Очевидно, что при этом в $O$ - и $T$-подрешетках происходят структурные переходы, противоположные вышеописанным.

Кроме вышерассмотренной коллоидно-дисперсной микрофазы, наноразмерные объемы которой когерентно включены в кристаллическую решетку $\alpha$-фазы титана, в порошковых частицах имеются микровключения состава $\mathrm{Ti}_{x} \mathrm{~A}_{y}$ и $\mathrm{Ti}_{x} \mathrm{~B}_{y} \mathrm{C}_{z}$, содержащие атомы внедрения $\{A ; B ; C\}=\{\mathrm{H} ; \mathrm{C} ; \mathrm{N} ; \mathrm{O}\}$. Эти инородные по отношению к $\alpha$-фазе титана микрофазы имеют кристаллические решетки, отличные от ГПУ-решетки $\alpha$-титана. Благодаря отклонениям элементного состава этих микрофаз от стехиометрического, в них могут, в свою очередь, происходить структурные фазовые переходы, также оставляющие неизменной тип их кристаллической решетки [3-5]. Очевидно, что эти переходы обусловлены недостаточной концентрацией атомов внедрения, входящих в кристаллическую решетку соответствующих инородных микрофаз. В качестве примера на рис. 5 приведены температурные зависимости параметров кристаллической решетки обнаруженных в порошковых частицах кубических микрофаз нестехиометрического состава: мононитрида титана $\mathrm{TiN}_{1-x} \square_{x}$ и карбонитрида титана $\mathrm{Ti}_{2} \mathrm{C}_{1-y} \mathrm{~N}_{1-x} \square_{x}$, где $\square_{x}, \square_{y}-$ концентрации структурных вакансий в подрешетках азота и углерода соответственно. (В химических формулах микрофаз символом „ $\square “$ (пустой квадрат) обозначены, как это общепринято в литературе, структурные вакансии в соответствующих подрешетках).

Полученные результаты свидетельствуют об аномалиях изменения параметров решетки вышеуказанных инородных микрофаз в интервале температур $\Delta T_{t r}=200-500^{\circ} \mathrm{C}$, которые также можно связать с обратимыми (и почти безгистерезисными) изменениями параметров дальнего порядка при структурных фазовых переходах в подрешетках соответствующих микрофаз.

Как следует из теоретического анализа [3-5], в нестехиометрическом кубическом нитриде титана при варьировании температуры должен наблюдаться лишь
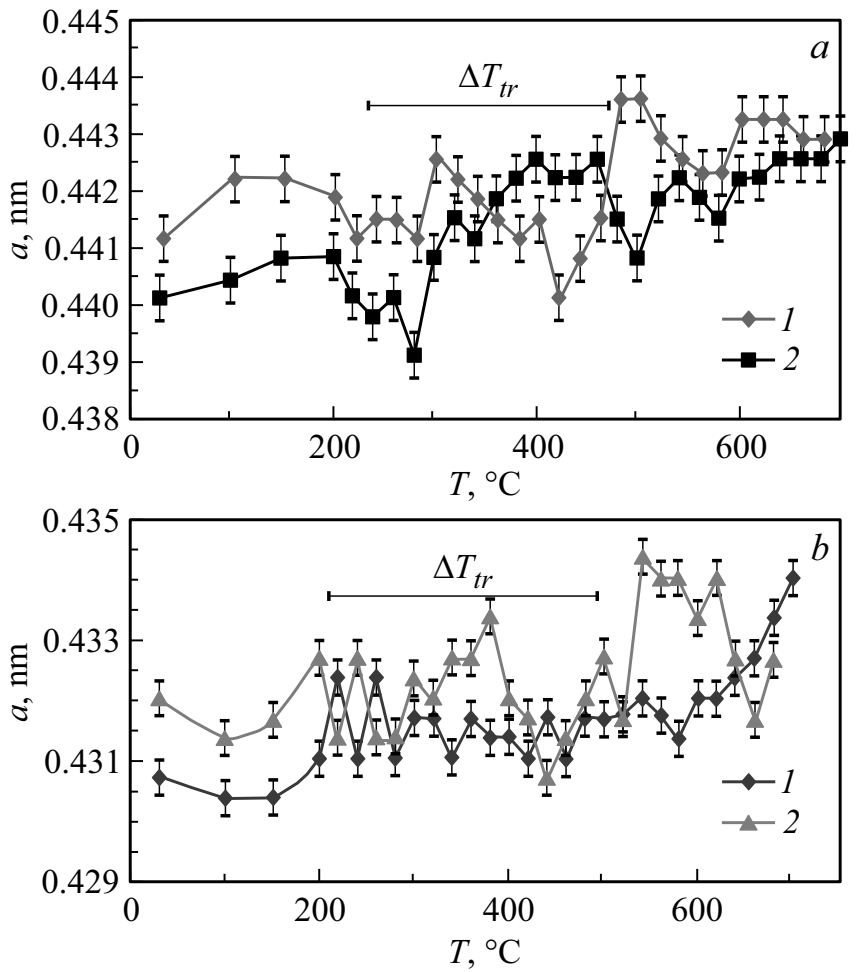

Рис. 5. Изменение параметра кристаллической решетки мононитрида $\mathrm{TiN}_{1-x} \square_{x}(a)$ и карбонитрида титана $\mathrm{Ti}_{2} \mathrm{C}_{1-x} \square_{x} \mathrm{~N}_{1-y} \square_{y}$ (b) при нагреве (1) и охлаждении (2) порошкового образца. Горизонтальными линиями отмечены температурные интервалы $\Delta T_{t r}$ соответствующих фазовых переходов. Символ $\square$ обозначает структурную вакансию.

один тип сверхструктуры и один параметр дальнего порядка, соответствующий единственному структурному фазовому переходу в подрешетке азота. В то же время, нестехиометрический карбонитрид титана характеризуется двумя сверхструктурными типами, двумя параметрами дальнего порядка $\left(\eta_{\mathrm{C}}, \eta_{\mathrm{N}}\right)$ и двумя структурными переходами в подрешетках азота и углерода. Однако во всех случаях при таких переходах внедренные атомы перераспределяются между геометрически и энергетически однотипными октаэдрическими междоузлиями в элементарной ячейке соответствуюшей ГЦК-подрешетки титана. Поэтому можно полагать, что в этих, а также других, обнаруженных в порошковом $\alpha$-титане ГЦК-микровключениях, структурные превращения указанного типа не будут вносить заметный вклад в энергопоглощение/энерговыделение на ДСК-графиках, поскольку они являются размытыми фазовыми переходами, близкими к безгистерезисным фазовым переходам второго рода $[4,18,19]$. Их температурное размытие связано с большими структурными флуктуациями, относительная стабилизация которых обусловлена значительными временами релаксации системы при не слишком высоких гомологических температурах перехода [19].

Вместе с тем, необходимо отметить, что результаты рентгеноструктурного анализа в данном случае не могут содержать сведения о наличии сверхтруктурных ли- 
ний на соответствующих дифрактограммах из-за весьма малой суммарной брутто-концентрации участвующих в фазовых переходах микрофазных включений, а также из-за существенного различия в значениях атомных факторов титана и образующих сверхструктурные подрешетки примесных атомов [20]. Поэтому заключения о существовании сверхструктурных переходов в $\alpha$-титане и сопутствующих инофазных микроструктурных включениях в данном случае базируются лишь на косвенных доказательствах. Для прямого и надежного обнаружения структурных фазовых переходов в микропримесном $\alpha$-титане необходимо проведение дополнительных высокотемпературных нейтронографических исследований.

\section{4. Выводы}

1. Методами термоанализа (ДСК, ТГА, РСА) и масспектрометрии показана возможность существования упорядоченных (сверхструктурных) микрообластей коллоидных размеров в твердом растворе примесей внедрения в $\alpha$-титане, а также в инородных микрофазах, содержащихся в микропримесном порошковом $\alpha$-титане.

2. Определены термодинамические и микроструктурные характеристики сверхструктурных фазовых переходов, происходящих в микрообластях и микрофазах порошкового $\alpha$-титана при его термоциклировании.

3. В рамках приближения среднего поля получены оценки энергий межатомного взаимодействия примесных атомов, внедренных в $O$ - и $T$-подрешетках $\alpha$-титана и локализованных в первой и второй координационных сферах этих подрешеток: $\bar{u}_{i i}^{O} \approx 0.5 \bar{u}_{i i}^{T} \approx-0.02 \mathrm{eV}$.

\section{Благодарности}

Авторы выражают благодарность А.И. Малкину за предложенную тему и ее финансирование.

Работа выполнена на оборудовании ЦКП ФМИ ИФХЭ PAH.

\section{Конфликт интересов}

Авторы заявляют, что у них нет конфликта интересов

\section{Список литературы}

[1] Металлические порошки и порошковые материалы. Справочник / Под ред. М.И. Алымова, Ю.В. Левинского. Научный мир, М. (2018). 610 с.

[2] А.М. Захаров. Диаграммы состояния двойных и тройных систем. Металлургия, М. (1990). 240 с.

[3] А.А. Ремпель, А.И. Гусев. Нестехиометрия в твердом теле. Физматлит, М. (2018). 604 с.

[4] А.А. Смирнов. Теория фазовых превращений и размещения атомов в сплавах внедрения. Наук. думка, Киев (1992). $280 \mathrm{c}$.

[5] В.Н. Бугаев, В.А. Татаренко. Взаимодействие и распределение атомов в сплавах внедрения на основе плотноупакованных металлов. Наук. думка, Киев (1989). 184 с.
[6] M. Fudjimoto. The physics of structural phase transitions. 2 ed. Springer Sci. Publ. N.Y. (2005). 283 p.

[7] Е.Н. Каблов. Вестн. РАН 82, 6, 520 (2012).

[8] М.Ю. Колеров, В.С. Спектор, С.В. Скворцова, А.М. Мамонов, Д.Е. Гусев, Г.В. Гуртова. Титан, 2, 48, 42 (2015).

[9] G. Lutjering, J.C. William. Titanium. Springer-Verlag, Berlin (2007). $431 \mathrm{p}$.

[10] А.П. Бровко, И.Н. Бекман. Изв. АН СССР. Металлы 1, 95 (1982).

[11] C.W. Greff, D.R. Trinkle, R.C. Albers. J. Appl. Phys. 90, 2221 (2001).

[12] D. Errandonea, Y. Meng, M. Somayazulu. Physica B 355, 116 (2005).

[13] G.S. Bezruchko, S.V. Razorenov, G.I. Kanel, V.E. Fortov. In: Shock compression of condensed matter / Ed. M. Furnish. Mellville, N. Y. (2006). P. 92.

[14] Жиляев, В.А. Попов, А.Р. Шарафутдинов, В.Н. Даниленко. Письма о материалах 1, 203 (2011).

[15] В.А. Борисенок, М.В. Жерноклетов, А.Е. Ковалев, А.М. Подурец, В.Г. Симаков, М.И. Ткаченко. Физика горения и взрыва 50, 13 (2014).

[16] E. Correta, G.T. Gray III, A.C. Lawson. J. Appl. Phys. 100, 013530 (2006).

[17] Т.П. Черняева, В.М. Грицина. Вопросы атомной науки и техники, 2, 15 (2008).

[18] А.Г. Хачатурян. Теория фазовых превращений и структура твердых растворов. Наука, М. (1974). 384 с.

[19] Б.Н. Ролов, В.Э. Юркевич. Физика размытых фазовых переходов. Изд-во Ростовского ун-та, Ростов (1983). 320 с.

[20] Л.И. Миркин. Справочник по рентгеноструктурному анализу поликристаллов. Физматгиз, М. (1961). 863 с.

Редактор К.В. Емцев 